\title{
Uptake of Extracellular Enzyme by a Novel Pathway Is a Major Determinant of Cathepsin L Levels in Human Macrophages
}

John J. Reilly, Jr., Peart Chen, Laura Zenzius Sailor, Robert W. Mason, ${ }^{*}$ and Harold A. Chapman, Jr. Department of Medicine, Brigham and Women's Hospital and Harvard Medical School, Boston, Massachusetts 02115; and

*Department of Biochemistry and Nutrition, Virginia Polytechnic Institute and State University, Blacksburg, Virginia 24061

\begin{abstract}
The phorbol myristate acetate (PMA)-differentiated myelomonocytic cell line, THP-1, and human alveolar macrophages contain the cysteine proteinase cathepsin $L$. This enzyme is synthesized as a 43-kD proenzyme and processed to the active 25-kD form. Differentiation of THP-1 cells in the presence of human serum resulted in a increase in the size of the vacuolar compartment and the accumulation of more $25-\mathrm{kD}$ cathepsin $\mathrm{L}$ antigen, as compared with THP-1 cells differentiated in the presence of fetal calf serum. Cells cultured in both types of sera have equivalent levels of cathepsin $L$ mRNA. Metabolic labeling experiments demonstrated equivalent rates of synthesis, processing to the active form, and persistence in both culture conditions. An extracellular source of enzyme was documented by immunoblotting human serum which demonstrated 25-kD cathepsin $L$ antigen; furthermore, we demonstrated that both THP-1 cells, differentiated in human serum, and human alveolar macrophages take up the 43-kD proenzyme and process it to the 25-kD form. Thus, human serum contains a factor(s) that induces both a marked increase in the size of the vacuolar compartment in differentiated THP-1 cells and a novel pathway that is responsible for the uptake and processing of extracellular cathepsin $\mathbf{L}$. The activity of this inducible pathway is a major determinant of levels of intracellular cathepsin L. Cathepsin $L$ is a potent elastase and the regulation of its uptake and processing may play a role in the pathogenesis of disease processes characterized by the destruction of elastin, such as pulmonary emphysema. (J. Clin. Invest. 1990. 86:176-183.) Key words: cysteine proteinase - differentiation - elastase • lysosomes - THP-1 cell line
\end{abstract}

\section{Introduction}

Current concepts regarding the pathogenesis of emphysema postulate that elastin degradation is a critical component in the development of this debilitating chronic lung disease (1). It has been suggested that lung macrophages play an important role in the connective tissue destruction characteristic of this disorder (2). We have previously reported that human macrophages are capable of degrading elastin by a contact-dependent process that involves one or more cysteine proteinases (3).

Address reprint requests to Dr. Reilly, Respiratory Division, Department of Medicine, Brigham and Women's Hospital, 75 Francis Street, Boston, MA 02115.

Received for publication 31 October 1989 and in revised form 27 February 1990.

J. Clin. Invest.

(c) The American Society for Clinical Investigation, Inc. 0021-9738/90/07/0176/08 $\$ 2.00$

Volume 86, July 1990, 176-183
There is some controversy concerning the enzyme(s) involved in extracellular elastin degradation, however, in that Senior and colleagues (4) reported that human alveolar macrophages, after $24 \mathrm{~h}$ in culture, degrade elastin by a process that is inhibitable by tissue inhibitor of metalloproteinases (TIMP). In connective tissue matrices, the cooperative participation of the serine proteinases plasminogen activator and plasmin(ogen) is required for measurable elastolysis to take place $(3,5,6)$. Human alveolar macrophages synthesize and express cathep$\sin \mathrm{L}$, which is an acidic cysteine proteinase that is a potent elastase $(7,8)$. This enzyme is synthesized as a $43-\mathrm{kD}$ precursor and then processed to an active $25-\mathrm{kD}$ enzyme via a $34-\mathrm{kD}$ intermediate. The 34-kD intermediate also has some enzymatic activity (9). In addition to the intracellular accumulation of cathepsin $L$, it has also been reported that human alveolar macrophages secrete the $43-\mathrm{kD}$ form of the enzyme in culture (7).

We sought to examine the factors that regulate the accumulation of cathepsin L by human macrophages. In earlier work, it was demonstrated that human peripheral blood monocytes do not contain appreciable cathepsin L mRNA, whereas human alveolar macrophages contain demonstrable levels of a 1.5-kB mRNA transcript encoding for cathepsin L (7). Thus, the expression of cathepsin L occurs at some point during the differentiation from monocyte to tissue macrophage. We used a human cell line (THP-1) as a model system to explore cathepsin L regulation. The THP-1 cell line has myelomonocytic characteristics and can be differentiated into a macrophage-like cell by exposure to retinoids and phorbol esters $(10,11)$. The data demonstrate that human macrophages have several independent mechanisms for cathepsin $\mathrm{L}$ accumulation and document the contribution of uptake of extracellular enzyme to steady-state intracellular cathepsin $\mathrm{L}$ levels.

\section{Methods}

Cell culture. THP-1 cells were obtained from the American Type Culture Collection, Rockville, MD. Cells were cultured in RPMI-1640 with $100 \mu \mathrm{g} / \mathrm{ml}$ streptomycin, $100 \mathrm{U} / \mathrm{ml}$ penicillin, $5 \times 10^{-5} \mathrm{M} 2$-mercaptoethanol (RPMI), and $10 \%$ heat-inactivated (HI) fetal calf serum (HIFCS; Hyclone Laboratories, Logan, UT). Cells were maintained at $37^{\circ} \mathrm{C}, 100 \%$ humidity, and $5 \% \mathrm{CO}_{2}$. Cells were differentiated at a concentration of $10^{6}$ cells $/ \mathrm{ml}$ in either RPMI $/ 10 \%$ FCS or RPMI $/ 20 \%$ human serum by the addition of phorbol myristate acetate (PMA) (Sigma Chemical Co., St. Louis, MO) to give a final concentration of $18 \mathrm{nM}$. During the differentiation process, care was taken to avoid exposure of the PMA or cells plus PMA to direct light. Except as noted, all experiments done with differentiated cells were performed $72 \mathrm{~h}$ after the addition of PMA.

1. Abbreviation used in this paper: $\mathrm{HI}$, heat-inactivated (FCS or human serum). 
Human alveolar macrophages were collected as previously described (3). In brief, normal volunteers underwent bronchoalveolar lavage under a protocol approved by the institutional committee for the protection of human subjects from research risks. The collected lavage specimen was placed on ice and then centrifuged at $300 \mathrm{~g}$ to pellet the cells. The cells were resuspended in Dulbecco's modified Eagle's medium (DME) with $20 \mathrm{mM}$ Hepes, $100 \mathrm{U} / \mathrm{ml}$ penicillin, and $100 \mu \mathrm{g} / \mathrm{ml}$ streptomycin. These alveolar macrophages were then used for the experiments described below.

Measurement of rates of pinocytosis and quantitation of the size of the vacuolar compartment. Swanson and colleagues (12) have reported that the use of Lucifer yellow $\mathrm{CH}$ allows the determination of rates of pinocytosis and the size of the vacuolar compartment. The uptake of Lucifer yellow within the first hour represents pinocytotic ingestion; levels after $24 \mathrm{~h}$ are more reflective of the size of the larger endocytic compartment, which displays slower kinetics.

Differentiated THP-1 cells were incubated with $1 \mathrm{mg} / \mathrm{ml}$ Lucifer yellow (Molecular Probes, Eugene, OR) for $0-24 \mathrm{~h}$ at $37^{\circ} \mathrm{C}, 100 \%$ humidity, $5 \% \mathrm{CO}_{2}$. After 0-24 h, the cells were washed extensively with phosphate-buffered saline (PBS) and lysed in PBS/1\% Triton X-100/0.5\% deoxycholate. Fluorescence of intracellular Lucifer Yellow was measured in a fluorescence spectrophotometer (model 10S, Perkin-Elmer Corp., Norwalk, CT) with excitation at $428 \mathrm{~nm}$ and emission monitored at $540 \mathrm{~nm}$. Preliminary experiments demonstrated that the uptake of Lucifer yellow was proportional to probe concentration. Rates of pinocytosis were measured by quantitating Lucifer yellow uptake over 30-90 min. The size of the endocytic compartment was determined by quantitating uptake of Lucifer yellow in cells that had been exposed to the dye for $24 \mathrm{~h}$.

mRNA analysis. Total cellular RNA was extracted from THP-1 cells by the guanidinium isothiocyanate/ $\mathrm{CsCl}$ method (13). RNA was electrophoresed ( $15 \mu \mathrm{g} / \mathrm{lane}$ ) in formaldehyde/agarose gels and transferred to nitrocellulose (Northern blotting) or various amounts of RNA were applied directly to nitrocellulose (dot blotting) (14). The cDNA probe used was an 800-bp cDNA of cathepsin L isolated from a human kidney cDNA library and subcloned in the plasmid PUC13 (15). The actin probe used was a gift of Dr. Jeff Leiden (Howard Hughes Medical Institute Research Laboratories, University of Michigan Medical Center, Ann Arbor, MI). The filters were baked, prehybridized, and hybridized with ${ }^{32} \mathrm{P}$-labeled nick-translated cDNA (16). The filters were washed and exposed to Kodak XR-5 film (Eastman Kodak Co., Rochester, NY) at $-70^{\circ} \mathrm{C}$ for $12-48 \mathrm{~h}$.

Metabolic labeling and immunoprecipitation. Metabolic labeling, immunoprecipitation and autoradiography were done as previously reported, with minor modifications (7). 10 million differentiated THP-1 cells in $25-\mathrm{cm}^{2}$ tissue culture flasks were labeled in $4 \mathrm{ml}$ of methionine-free DME containing $1 \mathrm{mg} / \mathrm{ml}$ bovine serum albumin (BSA) and $500 \mu \mathrm{Ci}$ of $\left[{ }^{35} \mathrm{~S}\right]$ methionine for $2-6 \mathrm{~h}$ as noted at $37^{\circ} \mathrm{C}, 5 \%$ $\mathrm{CO}_{2}, 100 \%$ humidity. 24-h labeling experiments were modified by including $10 \%$ (vol/vol) of methionine containing DME in the flask. After the labeling period, the cells were washed three times with PBS and then either lysed or changed to tissue culture media for the specified chase period. Cells were lysed in PBS plus 1\% Triton X-100, 10 mM EDTA, 2 mM phenylmethanesulfonyl fluoride, $100 \mathrm{U} / \mathrm{ml}$ Trasyslol (Sigma Chemical Co.), and $\mathbf{0 . 5 \%}$ deoxycholate. The cells were subjected to three cycles of freeze-thawing, scraped with a rubber policeman, and then clarified by centrifugation at $14,000 \mathrm{~g}$ for $15 \mathrm{~min}$.

Immunoprecipitation was performed after clarification of samples with $12.5 \mathrm{mg}$ of Protein A-Sepharose (Sigma Chemical Co.) and $15 \mu \mathrm{l}$ of normal rabbit serum. To ensure that quantitatively comparable samples were being studied, three methods were used for determining sample size. The first consisted of choosing a volume of lysate from pulsed cells containing $10^{7} \mathrm{cpm}$ and sampling an identical volume of cell lysate from subsequent chase samples. The second consisted of scraping cells off the tissue culture plate and counting in a hematocytometer before lysis. The volume of lysis buffer was adjusted so each sample had the same concentration of cells and identical volumes were used for immunoprecipitations. Lastly, total protein content of cell lysate was determined by the method of Lowry et al. (17) and sample volumes were calculated to give equivalent protein content. After the initial clarification, sodium dodecyl sulfate (SDS) was added to the samples in sufficient quantity to give a final concentration of $0.2 \%$. The samples were than incubated at room temperature for $2 \mathrm{~h}$ with 15 $\mu \mathrm{l}$ of rabbit anti-human cathepsin $\mathrm{L}$ antibody. Protein A-Sepharose $(6.25 \mathrm{mg})$ was then added for an additional $30 \mathrm{~min}$ at room temperature. The beads were then washed at least four times in PBS $/ 0.5 \%$ Triton/0.1\% SDS and complexes were removed by boiling in reduced sample buffer and electrophoresed on SDS/10\% (wt/vol) polyacrylamide gels. The gels were stained in Coomassie blue, destained, soaked in $16 \%$ salycylic acid $1 \%$ glycerol, and dried. Autoradiography was then performed using $\mathrm{XR} 5$ film at $-70^{\circ} \mathrm{C}$.

Western blotting. This was performed as previously described (7). Briefly, $10^{7}$ THP-1 cells or $8 \times 10^{6}$ human alveolar macrophages per sample were lysed as described above. After initial clarification by centrifugation, total cellular protein was extracted as described by Wessel and Flugge (18). These pellets were resuspended in reduced sample buffer and electrophoresed on 10\% SDS-PAGE. The electrophoresed proteins were then transferred to nitrocellulose by means of a Transblot apparatus (Bio-Rad Laboratories, Richmond, CA) using buffers as described by Burnette (19). Nonfat dried milk (5\%, wt/vol) in PBS was used subsequently to block nonspecific protein adherence during the antibody staining. Primary antibody staining with rabbit anti-human cathepsin $L$ was carried out for $2 \mathrm{~h}$ at room temperature. Secondary antibody staining was performed under similar conditions using ${ }^{125}$ I-coupled goat anti-rabbit IgG. After drying of the nitrocellulose filter, autoradiography was performed.

Uptake of pro-cathepsin $L$. W138 VA13 fibroblasts were obtained from the American Type Culture Collection. These were cultured in DME/10\% HIFCS. Conditioned media containing pro-cathepsin L was made by washing confluent monolayers of fibroblasts three times with PBS. The cells were then incubated for $24 \mathrm{~h}$ in DME plus $10 \mathrm{mM}$ $\mathrm{NH}_{4} \mathrm{Cl}$. The $\mathrm{NH}_{4} \mathrm{Cl}$ disrupts lysosomal $\mathrm{pH}$ gradients and results in the secretion of the proenzyme forms of lysosomal enzymes (20). The media was harvested at $24 \mathrm{~h}$, centrifuged at $300 \mathrm{~g}$ to remove cellular debris, and then concentrated 100-200-fold using a positive-pressure filter (Amicon Corp., Danvers, MA). This concentrated media was then used as a source of pro-cathepsin L for Western blots.

Uptake demonstrated by Western blots was performed as follows: THP-1 cells were differentiated with 18 nM PMA as described above. At $72 \mathrm{~h}$ postdifferentiation, the cells were changed to fresh media with or without the addition of concentrated WI38 supernatant. $24 \mathrm{~h}$ later, $10^{7}$ cells were lysed in PBS/1\% Triton X-100 and Western blotting was performed as outlined above. These experiments were also performed in the presence of $10 \mathrm{mM}$ mannose-6-phosphate, $100 \mathrm{mM}$ mannose, and $12.5 \mathrm{mg} / \mathrm{ml}$ fucoidan (all sugars obtained from Sigma Chemical Co.) in an attempt to delineate the pathways involved in uptake. Experiments involving human alveolar macrophages were performed by culturing freshly isolated macrophages in DME plus $0.25 \mathrm{mg} / \mathrm{ml} \mathrm{BSA}$. To this, supernatant with or without saccharides was added. After $24 \mathrm{~h}$ at $37^{\circ} \mathrm{C}, 5 \% \mathrm{CO}_{2}$ cells were processed as outlined for THP-1 cells.

\section{Results}

Differentiation induces cathepsin $L$ synthesis. In the undifferentiated state, the THP-1 cell has myelomonocytic characteristics. It is similar to peripheral blood monocytes in that it does not contain detectable quantities of cathepsin L. Differentiation of THP-1 cells with $18 \mathrm{nM}$ PMA results in a cell with the morphologic characteristics of a macrophage, including adherence. Given the fact that differentiated peripheral blood monocytes and human alveolar macrophages synthesize cathepsin L, we sought to determine whether such differentiation results in the induction of cathepsin L synthesis (7). Fig. 1 displays the analysis of levels of mRNA encoding cathepsin $L$ 


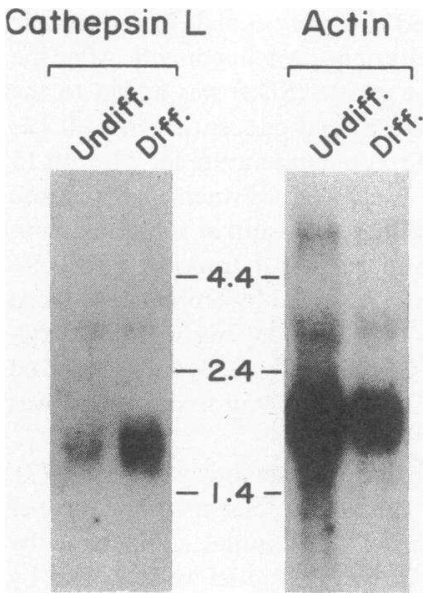

Figure 1. Induction of cathep$\sin \mathrm{L}$ mRNA by differentiation. Northern blot of cathep$\sin \mathrm{L}$ mRNA in undifferentiated THP- 1 cells and THP- 1 cell $72 \mathrm{~h}$ after exposure to 18 nM PMA demonstrating marked increase in the $1.5-\mathrm{kb}$ cathepsin L mRNA transcript after differentiation. The blot was then stripped and reprobed for actin mRNA as a control for amount of RNA loaded. Markers are given in kilobases (kb).

in undifferentiated and differentiated THP-1 cells. Fig. 1 (left) is a Northern blot showing a small amount of $1.5-\mathrm{kb}$ cathepsin $\mathrm{L}$ mRNA in undifferentiated cells in the left lane and easily detectable cathepsin L mRNA in differentiated THP- 1 cells in the right lane. The accompanying panel (Fig. 1, right) shows the same blot probed with a probe for actin mRNA to demonstrate the relative amounts of mRNA present in each lane. Quantitative dot blotting of THP-1 mRNA demonstrated that differentiation results in a 10-fold (mean of seven experiments) increase in cathepsin $\mathrm{L}$ mRNA levels (data not shown).

Effects of human serum on THP-1 cells. Previous work has demonstrated that incubating monocytes isolated from peripheral human blood in $20 \%$ human serum will induce differentiation of these cells into cells that resemble macrophages (21). We sought to determine whether the substitution of human serum for FCS in the cultures of differentiated THP-1 cells would have any effect on cell morphology or cathepsin L levels.

Fig. 2 shows a representative photomicrograph of THP-1 cells differentiated with $18 \mathrm{nM}$ PMA and photographed $72 \mathrm{~h}$ after culture in RPMI 1640 with either $10 \%$ HIFCS or $20 \%$ HI human serum. The same morphologic differences were observed when cells differentiated with PMA in the presence of $20 \%$ HIFCS were compared to cells similarly differentiated in the presence of $20 \% \mathrm{HI}$ human serum. The cells cultured in human serum have an easily visible and dramatic increase in the number of vacuoles visible within the cell. Other investigators have reported the use of a variety of compounds to determine both the extent and $\mathrm{pH}$ of the lysosomal compartment. These compounds include fluorescein isothiocyanate (FITC), FITC-Dextran, Texas red ovalbumin, and Lucifer yellow (12, 22-24). Fig. $2 B$ shows in graphical form the results of four experiments (demonstrating that the vacuolar compartment is $85 \pm 38 \%$ larger) in cells cultured in human serum, using incubation with Lucifer yellow for $24 \mathrm{~h}$ and then measuring fluorescence of cell lysates. The $85 \%$ increase in vacuolar compartment size shown in Fig. $2 B$ may be an underrepresentation, since under fluorescence microscopy, there was visible fluorescence in only a portion of the vacuoles visible under phase-contrast microscopy. This phenomenom was also observed using FITC and FITC-Dextran (data not shown). The induction of this morphologic change was not blocked by mixing FCS and human serum during the cell culture (data not shown).
A
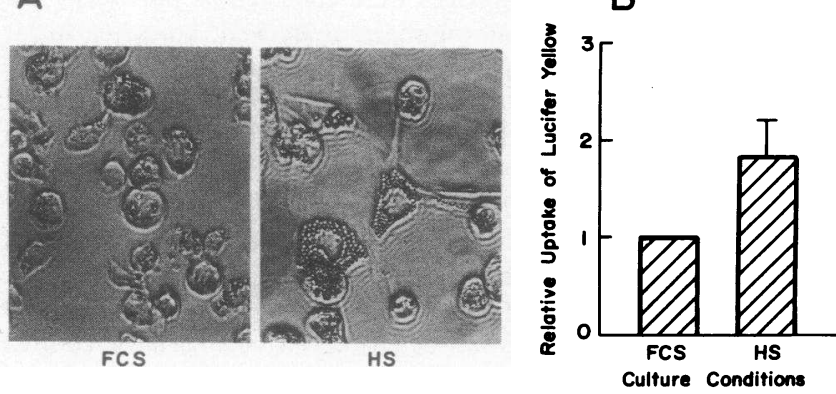

Figure 2. Human serum induces an increase in the vacuolar compartment in differentiated THP- 1 cells. $(A)$ Photomicrograph of THP-1 cells $72 \mathrm{~h}$ after differentiation with $18 \mathrm{nM}$ PMA. Cells were cultured in RPMI plus fetal calf serum $(F C S)$ or human serum $(H S)$ as noted. Note the marked increase in vacuoles visible in cells cultured in human serum. $(B)$ Quantitation of increased vacuolar size by Lucifer yellow. Differentiated THP-1 cells in FCS or human serum as noted incubated with $1 \mathrm{mg} / \mathrm{ml}$ Lucifer yellow as outlined in methods. Measurement of fluorescence demonstrated $85 \pm 36 \%$ in crease in vacuolar compartment (mean $\pm \mathrm{SD}$ of four experiments).

This morphologic difference led us to question whether comparable differences in the levels of the lysosomal enzyme, cathepsin L, would be detectable. Fig. 3 shows a Western blot of THP-1 cell lysates developed with anti-cathepsin L antibody. The blot shows very little cathepsin $\mathrm{L}$ antigen visible in the cells cultured in FCS, but large quantities of the 25-kD form of cathepsin $\mathrm{L}$ are detected in lysates of cells cultured in

A
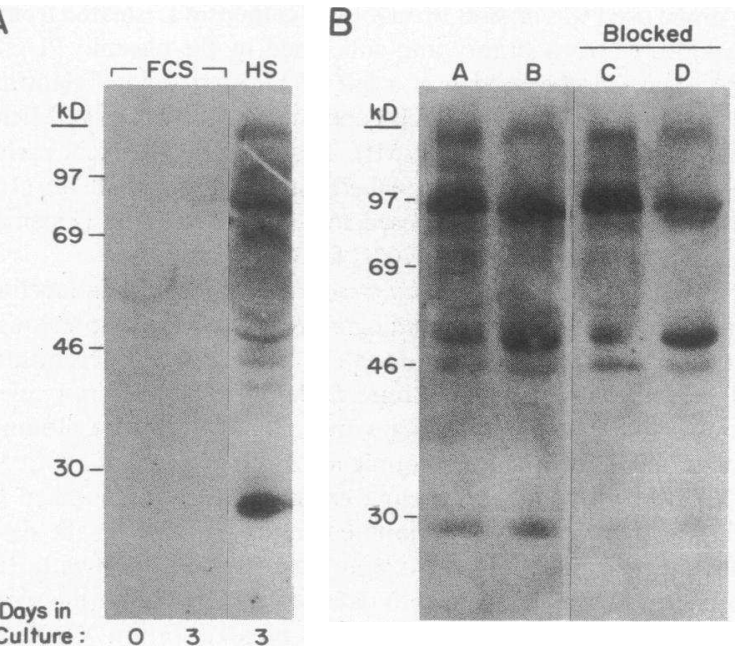

Figure 3. Cathepsin $\mathrm{L}$ antigen in differentiated THP-1 cells. $(A) \mathrm{Im}$ munoblot of THP-1 cell lysates showing no detectable cathepsin $\mathrm{L}$ antigen in THP-1 cells or THP-1 cell cultured in fetal calf serum $(F C S)$ for $3 \mathrm{~d}$ after exposure to $18 \mathrm{nM}$ PMA. In contrast, THP-1 cells cultured in human serum $(H S)$ for $3 \mathrm{~d}$ after exposure to $18 \mathrm{nM}$ PMA have clearly demonstrable $25-\mathrm{kD}$ cathepsin $\mathrm{L}$ antigen. $(B)$ Blocking experiment. Immunoblot showing cathepsin $\mathrm{L}$ antigen in THP-1 cells differentiated in the presence of human serum. Lanes $A$ and $B$ represent lysates of such cells probed with anticathepsin $L$ antibody and demonstrate 25-kD cathepsin $\mathrm{L}$ in both sets of cell lysates. Lanes $C$ and $D$ represent the same lysates probed with anticathepsin $\mathrm{L}$ antibody that has been preabsorbed with purified human cathepsin $\mathrm{L}$, demonstrating that the $25-\mathrm{kD}$ band does represent cathepsin $\mathrm{L}$. 
human serum. Heat inactivation of human serum at $56^{\circ} \mathrm{C}$ for 30 min did not block this induction, nor did extensive dialysis of human serum (molecular mass cutoff of $\sim 11,000$ daltons) (data not shown). Fig. $3 B$ confirms that this $25-\mathrm{kD}$ band represents cathepsin $\mathrm{L}$ by showing that the immunoreactivity is blocked by preincubating the antibody with purified cathepsin L. Thus, the morphologic changes visible in the cells in different culture conditions are accompanied by large differences in intracellular cathepsin $\mathrm{L}$ levels.

Comparison of cathepsin $L m R N A$ levels. We performed Northern and dot blotting for cathepsin L mRNA to establish whether or not the difference in the observed protein levels was the result of an increase in steady-state cathepsin L mRNA levels. Fig. 4 displays the results of this analysis. Fig. $4 A$ displays a Northern blot comparing cathepsin L levels in cells cultured in either FCS or HS. The same blot was then reprobed for actin mRNA as a control for total RNA loaded in the lane. Fig. $4 \mathrm{~A}$ demonstrates that cathepsin L mRNA levels are comparable under the two culture conditions. This was confirmed by doing dot blots for cathepsin L mRNA on serial dilutions of RNA isolated from differentiated THP-1 cells under the two different culture conditions (Fig. $4 \mathrm{~B}$ ). These analyses also demonstrated comparable cathepsin L mRNA levels. These mRNA level data (representative of six experiments) suggest that the factor(s) responsible for the increase in cathepsin $\mathrm{L}$ antigen do not change steady-state cathepsin L mRNA levels.

Cathepsin $L$ translation and posttranslational processing. We sought to establish whether the differences in antigen levels could be explained by differences in the rates of cathepsin $L$ translation or in the rates of posttranslational processing. We explored these factors by metabolic labelling of differentiated THP- 1 cells and immunoprecipitation of cell lysates after varying periods of chase in pulse-chase experiments. Fig. 5

A

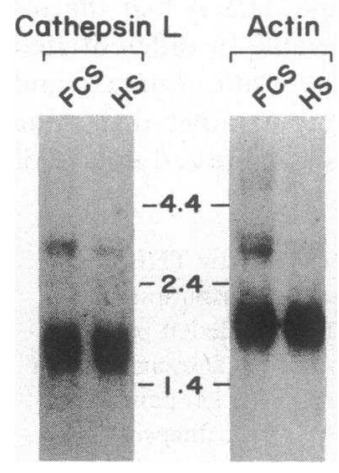

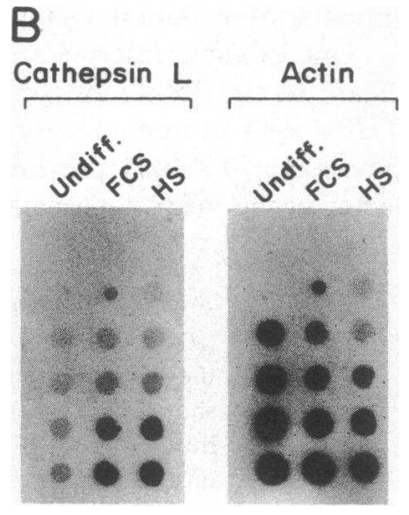

Figure 4. Comparison of cathepsin L mRNA levels in THP-1 cells cultured in fetal calf serum $(F C S)$ or human serum $(H S)$. (A) Northern blot showing comparable levels of $1.5-\mathrm{kb}$ cathepsin $\mathrm{L}$ mRNA transcript in THP-1 cells $72 \mathrm{~h}$ after differentiation in the presence of FCS or HS as noted. The blot was then stripped and reprobed for actin mRNA levels as a control for the amount of RNA loaded. Markers given in kilobases (kb). (B) Dot blot of cathepsin L mRNA levels containing increasing amounts $(0.1,0.5,1$, and $2 \mu \mathrm{g}$ RA, respectively) of THP-1 mRNA in each column. Probing for cathepsin L mRNA demonstrates comparable levels in cells differentiated in the presence of FCS or human serum as noted. Both contain much more (10-fold) than undifferentiated THP-1 cells. The blot was then stripped and reprobed for actin mRNA as a control for amount of RNA loaded.
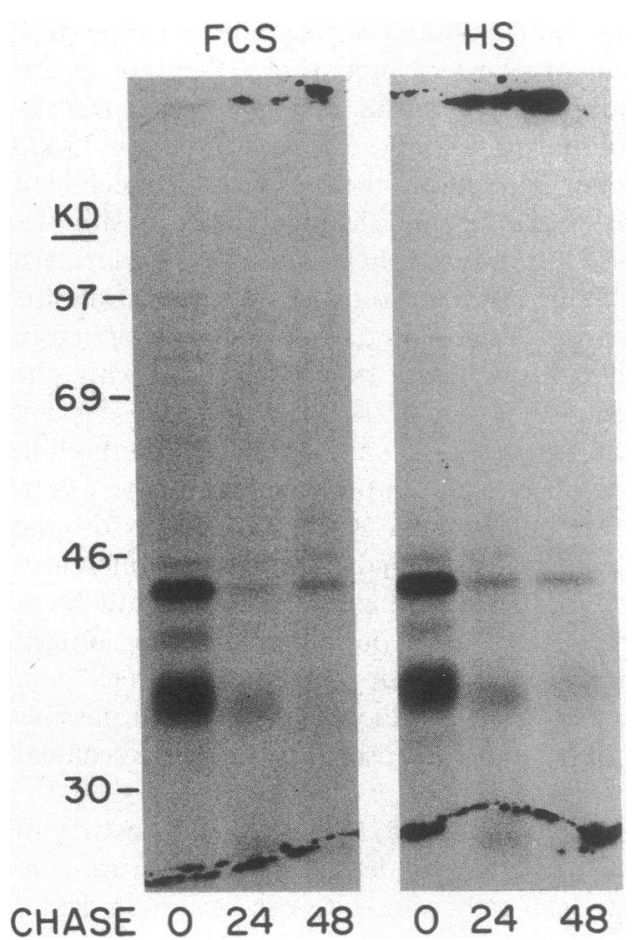

Figure 5. Biosynthesis of cathepsin L by differentiated THP-1 cells in the presence of fetal calf serum $(F C S)$ or human serum $(H S)$. Immunoprecipitation with anti-cathepsin $\mathrm{L}$ antibody of $\left[{ }^{35} \mathrm{~S}\right] \mathrm{methio}$ nine metabolically labeled THP-1 cells differentiated in the presence of FCS or HS as noted. Sample size determined as outlined in text. Cells were labeled overnight, then chased for periods noted. Under both culture conditions, the cells synthesize comparable amounts of 43-kD proenzyme and process it to $34-$ and $25-\mathrm{kD}$ forms at comparable rates.

shows an experiment representative of the five performed, with a 24-h label followed by up to a 48-h chase. As we have previously described in human alveolar macrophages, cathep$\sin \mathrm{L}$ is synthesized as a $43-\mathrm{kD}$ proenzyme and is then processed to a 34-kD intermediate (7). This intermediate, which has been demonstrated to have some enzymatic activity, is further processed to a $25-\mathrm{kD}$ active form of the enzyme. This 25-kD form is the dominant form detected on Western blotting of macrophage lysates. The band visible at $41-\mathrm{kD}$ in the 24 $h$ label lane probably represents the primary translation product before glycosylation, as this corresponds to the molecular weight of polypeptide encoded by the cathepsin L gene. Fig. 5 demonstrates that there is no apparent difference in the rate of translation of the cathepsin $\mathrm{L}$ gene, as evidenced by the comparable amounts of 43- and 34-kD cathepsin $L$ seen in the pulse lane of the figure. In addition, the rate of posttranslational processing appears comparable under the two different culture conditions, as evidenced by the similar amounts of 34and 25-kD antigen seen at 24 and $48 \mathrm{~h}$. The similar amounts of $25-\mathrm{kD}$ antigen also indicate that there is no obvious difference in the stability of the $25-\mathrm{kD}$ antigen in the two different culture conditions. These observations remain unchanged when the experiments are performed using total protein or cell number, as outlined in Methods, to determine sample size, rather than using comparable total counts.

Taken together with the mRNA analyses presented above, 
these data indicate that the observed differences in cathepsin $\mathrm{L}$ antigen levels seen on Western blots (Fig. 3) cannot be explained by differences in cathepsin $\mathrm{L}$ transcription, translation, posttranslational processing, or stability of the $25-\mathrm{kD}$ form of the enzyme. In addition, these experiments highlight the fact that there are significant differences in the sensitivities of the methods used to detect cathepsin $L$ antigen. Northern blotting and metabolic labeling experiments demonstrate the presence of cathepsin L mRNA and 34- and 25-kD cathepsin $L$ antigen in cells cultured under both conditions, while the immunoblots, done using roughly 10 times as many cells, fail to demonstrate the 34 - and $25-\mathrm{kD}$ antigen in cells cultured in FCS. The experiments described up to this point have examined each step of the intracellular synthesis of this lysosomal enzyme. Given the conclusion that the observed differences could not be explained by differences in protein synthesis or regulation within the cell, we hypothesized that the antigen seen on the immunoblots was not the result of intracellular (endogenous) synthesis, but represented uptake and possible processing of some form of cathepsin $\mathrm{L}$ from an extracellular source.

Uptake of extracellular enzyme. Immunoblotting of human serum was performed to determine if the serum contains detectable levels of cathepsin L. As can be seen in the far left lane of Fig. $6 \mathrm{~A}$, there was antigen detectable in human serum using the anti-cathepsin $\mathrm{L}$ antibody. Preabsorption of the antibody with purified cathepsin L demonstrated that the $25-\mathrm{kD}$ band seen in serum is in fact cathepsin L. Although there was some blocking of the higher molecular mass bands, there was no convincing evidence that pro-cathepsin $\mathrm{L}$ is present. Gel filtration chromatography demonstrated that the 25-kD antigen was eluted over a broad range of molecular mass, suggesting that under physiologic conditions some $25-\mathrm{kD}$ cathepsin $\mathrm{L}$ is bound to one or more serum proteins (data not shown).

We investigated whether these macrophages were capable of accumulating cathepsin $\mathrm{L}$ from the extracellular space and, if so, by what mechanism. Published reports have demonstrated that cathepsin $\mathrm{L}$ is the major product of transformed fibroblasts (9). We therefore performed preliminary experiments with the transformed lung fibroblast cell line, WI38
VA13, to determine if this particular line also synthesized cathepsin $\mathrm{L}$. The cells were cultured in the presence of $10 \mathrm{mM}$ $\mathrm{NH}_{4} \mathrm{Cl}$ to prevent lysosomal accumulation of the enzyme, resulting in secretion of lysosomal proenzymes (20). Immunoblotting (second lane, left panel, Fig. $6 \mathrm{~A}$ ) demonstrated that these culture conditions resulted in the secretion of $43-\mathrm{kD}$ procathepsin L, but no $34-$ or $25-\mathrm{kD}$ form of the enzyme was detected. Conditioned media produced in this fashion was concentrated by positive pressure ultrafiltration and used as a source of proenzyme for uptake experiments. Differentiated THP-1 cells were incubated with these concentrated supernatants for $24 \mathrm{~h}$. The cells were then lysed and immunoblotting performed to assess cathepsin $\mathrm{L}$ antigen levels. The right half of Fig. $6 \mathrm{~A}$ displays one such experiment. In this experiment, repeated five times, incubation of the differentiated THP-1 cells in human serum with pro-cathepsin $L$ results in an increase in the amount of $25-\mathrm{kD}$ cathepsin $\mathrm{L}$ antigen detectable by immunoblotting. Several pathways have been described for the uptake of extracellular lysosomal enzymes which involve recognition of saccharides that are added during glycosylation in the Golgi apparatus. In an attempt to define the pathway involved in the uptake of cathepsin $\mathrm{L}$, the uptake experiments were performed in the presence of $10 \mathrm{mM}$ mannose-6-phosphate, $100 \mathrm{mM}$ mannose, and $12.5 \mathrm{mg} / \mathrm{ml}$ fucoidan. The concentrations have been demonstrated to block uptake via the described saccharide recognition pathways (25-29). Fig. $6 B$ displays quantitation, as determined by densitometry of immunoblots, of the uptake of pro-cathepsin $\mathrm{L}$ and processing to the $25-\mathrm{kD}$ antigen with and without blocking concentrations of saccharides. This figure demonstrates that the increase in the $25-\mathrm{kD}$ cathepsin L antigen was not blocked by any of the saccharides used. Further experiments demonstrated that the presence of human serum was required for demonstrable uptake. If the human serum was removed at the time of adding the WI38 supernatant, uptake was not demonstrable by immunoblotting (data not shown).

One possible interpretation of these data is that the increase in the $25-\mathrm{kD}$ antigen demonstrable in differentiated THP-1 cells in human serum is not the result of uptake and processing of $43-\mathrm{kD}$ pro-cathepsin $\mathrm{L}$, but rather that some factor in the WI38 supernatant results in increased uptake of
A

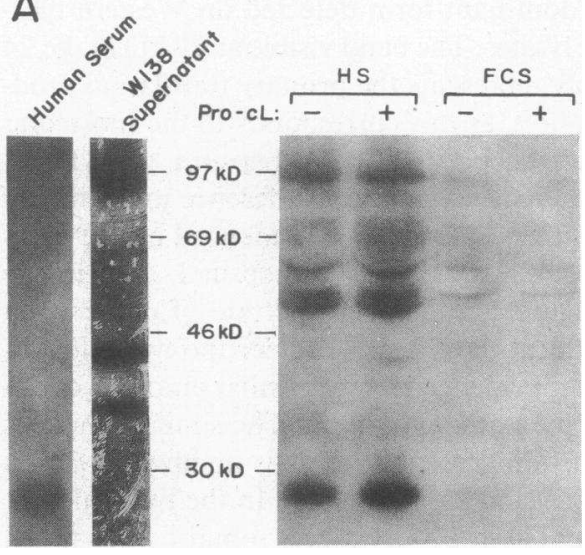

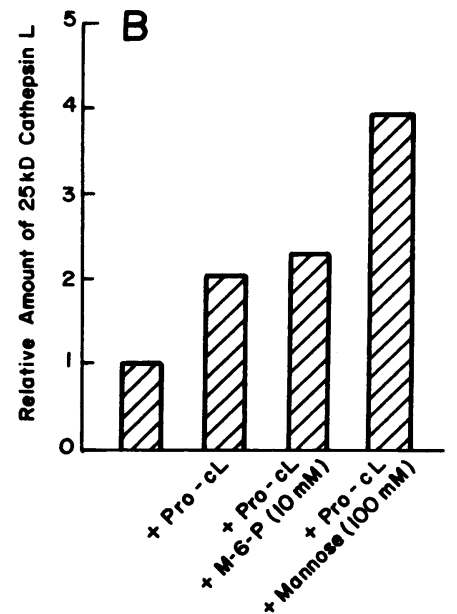

Figure 6. Uptake of procathepsin L by THP-1 cells. (A) Immunoblot demonstrating distribution of cathepsin $\mathrm{L}$ antigen. The left lane in the left panel shows $25-\mathrm{kD}$ cathepsin $\mathrm{L}$ antigen is demonstrable in human serum. The right lane in the left panel demonstrates the presence of $43-\mathrm{kD}$ procathepsin $\mathrm{L}$, but no 25-kD antigen, in concentrated supernatants from WI38 VA13 fibroblasts. The four lanes in the right panel depict the distribution of cathepsin $L$ antigen in THP-1 cell lysates. Cells were differentiated in the presence of fetal calf serum $(F C S)$ or human serum $(H S)$ as noted. The cells in human serum have demonstrable 25-kD cathepsin $\mathrm{L}$, which increases in amount after exposure to supernatants containing 43-kD pro-cathepsin L (Pro-cL). No such 25-kD antigen or increase is seen in cells cultured in FCS. (B) Quantitation of cathepsin L uptake. Relative amount of $25-\mathrm{kD}$ cathepsin $\mathrm{L}$ antigen in THP-1 cells cultured in human serum with or without added pro-cathepsin $\mathrm{L}$ (Pro-cL, as noted) as determined by densitometry of immunoblots, demonstrating an
increase in $25-\mathrm{kD}$ cathepsin $\mathrm{L}$ antigen in cells exposed to $43-\mathrm{kD}$ procathepsin $\mathrm{L}$ for $24 \mathrm{~h}$. This increase was not blocked by $10 \mathrm{mM}$ mannose-6phosphate, $100 \mathrm{mM}$ mannose, or $12.5 \mathrm{mg} / \mathrm{ml}$ fucoidan (not pictured). 
the $25-\mathrm{kD}$ antigen that is abundant in human serum. To explore this possibility, we repeated the experiments using human alveolar macrophages cultured in serum-free conditions. Incubation with concentrated WI38 supernatant was performed for $24 \mathrm{~h}$ in DME $/ 0.25 \mathrm{mg} / \mathrm{ml} \mathrm{BSA}$. The data, a representative example of which is illustrated in Fig. 7, demonstrate that human alveolar macrophages display behavior identical to that of the THP-1 cells cultured in human serum with respect to uptake of cathepsin $\mathrm{L}$, in that they take up exogenous cathepsin $\mathrm{L}$ and process it to the $34-$ and $25-\mathrm{kD}$ forms via a pathway that is not blocked by mannose, mannose-6-phosphate, or fucoidan. Densitometry of the immunoblots demonstrated uptake comparable to that seen in THP-1 cells in human serum as demonstrated in Fig. $6 B$ (data not shown). These data suggest that the increase in intracellular antigen levels is the result of uptake and processing of the procathepsin L in the WI38 supernatants, rather than an increase in uptake of the cathepsin $\mathrm{L}$ antigen in human serum.

The possibility that the accumulation of cathepsin $\mathrm{L}$ from the extracellular space was the result of an increase in fluid phase pinocytosis, rather than a more selective pathway, was evaluated by comparing the rates of pinocytosis among THP-1 cells cultured in the two different sera (12). Measurements of the rate of uptake of Lucifer yellow from $30 \mathrm{~min}$ to $4 \mathrm{~h}$ demonstrated no differences among the two culture conditions, suggesting that the increase in uptake of cathepsin $\mathrm{L}$ is not merely the result of an increase in the rate of nonspecific pinocytosis.

An attempt was made to remove cathepsin $L$ antigen from human serum in order to dissociate the factor(s) responsible for the induction of the uptake pathway from cathepsin $\mathrm{L}$ antigen and therefore presumably demonstrate the absence of $25-\mathrm{kD}$ cathepsin L on immunoblots of THP-1 cells cultured in cathepsin L-depleted human serum. Unfortunately, the available quantities of anti-cathepsin $\mathrm{L}$ antibody were insufficient to allow construction of an anti-cathepsin $\mathrm{L}$ affinity column. As outlined earlier, attempts to fractionate serum on the basis of apparent molecular mass to deplete cathepsin $\mathrm{L}$ also failed, as the antigen is widely distributed throughout the gel filtration eluant, presumably as the result of protein binding in serum. We were therefore unable to generate cathepsin L-depleted human serum.

\section{Discussion}

This paper presents data addressing the regulation of intracellular levels of a lysosomal cysteine proteinase, cathepsin $\mathbf{L}$. This acidic protease has broad substrate specificity, including the ability to degrade elastin. The data presented establish the

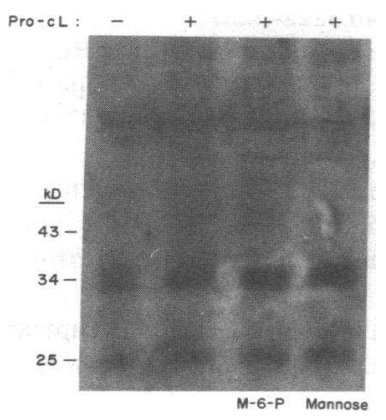

Figure 7. Uptake of pro-cathepsin L $($ Pro- $c L)$ by human alveolar macrophages. Immunoblot of cathepsin $\mathrm{L}$ antigen in lysates of human alveolar macrophages cultured in serum-free conditions (see text) with or without added pro-cathepsin L (as noted) demonstrating increased amounts of cathepsin $\mathrm{L}$ antigen in cells exposed to pro-cathepsin $\mathrm{L}$ for $24 \mathrm{~h}$. This increase was not blocked by $10 \mathrm{mM}$ mannose-6-phosphate or $100 \mathrm{mM}$ mannose. fact that the expression of detectable levels of cathepsin $L$ is the result of both the differentiation of myelomonocytic cells into macrophages (Fig. 1) and of the specific culture conditions to which the macrophages are exposed (Fig. 3).

Differentiation of THP-1 cells in the presence of human serum results in an $85 \%$ increase in the size of the vacuolar compartment, detectable by visual inspection and quantitated by the uptake of Lucifer yellow (Fig. 2). This increase is accompanied by an increase in the amount of detectable intracellular cathepsin $\mathrm{L}$. The data presented in this report establish that the increase in intracellular cathepsin $\mathrm{L}$ results from the acquisition and accumulation of the enzyme from an extracellular source. The data also demonstrate the PMA-induced differentiation alone does not result in the expression of cathepsin L uptake (Fig. $6 \mathrm{~A}$ ), but that the presence of human serum is required for demonstrable uptake activity. That this is the result of a factor(s) in human serum, as opposed to being prevented by an inhibitor in FCS, was confirmed by performing mixing experiments in which the cells were exposed to both FCS and human serum. These experiments demonstrated the same morphologic and antigenic changes as were seen in cells exposed to human serum alone. It has previously been reported in HeLa cells that incubation in human serum results in an increase in the number of visible vacuoles and an increase in the amount of acid phosphatase detectable cytochemically within the cells (30). Ahearn and colleagues (31) reported a $129 \%$ increase in the number of vacuoles staining for acid phosphatase in HeLa cells exposed to $100 \%$ human serum, a finding similar to the $85 \%$ increase noted in this report.

We then sought to establish at what regulatory site the factor(s) are operating to produce the observed increase in cathepsin $\mathrm{L}$ levels in cells cultured in human serum. Analysis of the levels of cathepsin L mRNA demonstrated equivalent message levels in the two culture conditions. Further experiments showed no differences in the rates of synthesis of the 43-kD precursor and subsequent processing to the $25-\mathrm{kD}$ active form in the two culture conditions. These data lead to the conclusion that the cells accumulate demonstrable cathepsin $\mathrm{L}$ antigen from an extracellular source.

Uptake of extracellular lysosomal enzymes is a well described process in fibroblasts and macrophages. Two principal pathways have been described, both of which depend on the recognition of saccharide residues on the glycosylated enzyme. The first is the mannose-6-phosphate receptor system (32). This consists of two receptors, one cation dependent and the other cation independent. One important function of this system is to target newly synthesized lysosomal enzyme precursors in the Golgi apparatus to the endosomal compartment. It has also been demonstrated to have the capability of taking up extracellular enzyme as well. The second is the mannose/fucose receptor. Originally described in hepatic tissue, this receptor system has also been demonstrated to be present in alveolar macrophages (33). As the name implies, this system recognizes mannose and fucose residues on glycoproteins and is capable of binding extracellular protein at the cell surface. Campbell demonstrated that alveolar macrophages were capable of ingesting a neutral serine proteinase, human neutrophil elastase, by a receptor-mediated process that also bound lactoferrin and cathepsin $G$ and later releasing quantities of active enzyme in response to hypoxic stress $(29,34,35)$. This binding and uptake was blocked by fucoidan. 
The data presented in this article demonstrate uptake of a lysosomal enzyme by a pathway independent of any of these described pathways. This was established by demonstrating uptake still takes place (Figs. $6 \mathrm{~B}$ and 7) in the presence of sufficient concentration of sugars to block binding of glycoproteins to the receptors (25-29). The existence of such a pathway is supported by several lines of circumstantial evidence. The first stems from observations made in patients with I cell disease. I cell disease is an autosomal recessive disorder characterized by a defect of phosphorylation of lysosomal enzyme precursors. As a result, these precursors are not recognized by the mannose-6-phosphate receptor. In cultured fibroblasts from these patients, intracellular lysosomal enzyme levels are low and the precursors can be demonstrated to be secreted into the extracellular environment (36). In other tissues, however, lysosomal enzyme levels are relatively normal, suggesting the existence of additional pathway(s) transporting precursors to the endosomal or lysosomal compartment (37). In cells that are deficient in the expression of the mannose-6phosphate receptor but are able to phosphorylate proenzymes appropriately, intracellular lysosomal enzyme levels are normal, once again suggesting an alternative pathway for lysosomal enzyme targeting (38). The uptake of cathepsin L reported here occurs by a mechanism independent of the described pathways that depend on carbohydrate recognition, constituting yet another mechanism by which macrophages can potentially accumulate lysosomal enzyme(s). Whether or not this pathway accounts for observations in I cell disease or mannose-6-phosphate receptor deficient cells remains to be determined.

The possibility exists that this pathway involves the uptake of enzyme bound to a carrier protein. The fact that immunoblotting of serum subjected to gel filtration chromatography demonstrates that cathepsin $\mathrm{L}$ antigen appears in fractions ranging from $>75$ to $\sim 25 \mathrm{kD}$ suggests that a much of the cathepsin $\mathrm{L}$ antigen is bound to one or more proteins. The data presented using human alveolar macrophages cultured in serum-free conditions make uptake via a carrier protein seem less likely, or at least imply that if a carrier protein is involved, it is one synthesized and secreted by the macrophages themselves or is found in the concentrated supernatants from WI38 fibroblasts.

Previous reports concerning cathepsin $L$ suggest that it should also be taken up by the mannose-6-phosphate pathway as well (39). Our use of immunoblotting to demonstrate uptake may have precluded demonstration of mannose-6-phosphate-dependent uptake. As discussed earlier, the lack of sensitivity of the immunoblotting is demonstrated by the fact that cathepsin L is not seen in immunoblots of THP-1 cells cultured in FCS, whereas more sensitive metabolic labeling studies demonstrate the presence of $25-\mathrm{kD}$ cathepsin $\mathrm{L}$ in these cells. The fact that uptake of extracellular enzyme is demonstrable by immunoblotting suggests that much more cathepsin $\mathrm{L}$ is taken up by the pathway described here than by the mannose or mannose-6-phosphate pathways. This is consistent with the conclusion that the activity of this pathway is responsible for the accumulation of the majority of intracellular cathepsin $\mathrm{L}$.

This role of extracellular enzyme uptake in determining intracellular levels of enzyme appears to be a novel mechanism for the regulation of lysosomal enzyme levels. In their report examining the induction of lysosomal enzymes in murine peritoneal macrophages, Morland and Morland (40) found that it is possible to selectively induce various lysosomal enzymes but that this induction was blocked by cycloheximide and concluded that the increase in enzyme levels is the result of increased synthesis. Odessey (41), in examining lysosomal enzyme activity after burn injury to skeletal muscle, found that the increase in cathepsin $\mathrm{D}, \mathrm{B}, \mathrm{H}$, and $\mathrm{L}$ activities was paralleled by increased glycoprotein synthesis and concluded that the observed increase was due to new enzyme synthesis. Livi and colleagues (42) examined the regulation of lysosomal $\alpha$-mannosidase-1 in Dictyostelium discoideum and demonstrated that intracellular levels of enzyme were closely paralleled by the rate of precursor synthesis, which in turn was a function of $\alpha$-mannosidase-1 mRNA levels in the cell (42). The mechanism described in this report is distinctly different in that markedly different levels of intracellular cathepsin $L$ are demonstrated under conditions where cathepsin L mRNA levels are identitical and the rate of precursor synthesis and subsequent processing to the $25-\mathrm{kD}$ antigen are comparable.

The biologic role of this pathway remains to be defined. It is possible that the exogenous pathway has a function other than enzyme accumulation. The other reported pathways involved in the trafficking of lysosomal enzymes have been reported to have additional functions as well (43-49). The important role that this mechanism has in the determination of intracellular enzyme levels suggests that the regulation of this pathway may play an important role in the regulation of lysosomal proteolysis by human macrophages.

\section{Acknowledgments}

Dr. Reilly is a Parker B. Francis Fellow in Pulmonary Research. Dr. Chapman is a Career Investigator of the American Lung Association.

This work was supported by National Institutes of Health grants HL-19170 and HL-07633 (NRSA) and grants from the Council for Tobacco Research-U.S.A. (to Drs. Chapman and Mason).

\section{References}

1. Janoff, A. 1985. Elastases and emphysema: current assessment of the protease-antiprotease hypothesis. Am. Rev. Respir. Dis. 132:417-433.

2. Reilly, J. J., and H. A. Chapman. 1988. Association between macrophage plasminogen activator activity and lung function in young cigarette smokers. Am. Rev. Respir. Dis. 138:1422-1428.

3. Chapman, H. A., O. L. Stone, and Z. Vavrin. 1984. Degradation of fibrin and elastin by intact human alveolar macrophages in vitro. $J$. Clin. Invest. 73:806-815.

4. Senior, R. M., N. L. Connolly, J. D. Cury, H. G. Welgus, and E. J. Campbell. 1989. Elastin degradation by human alveolar macrophages: a prominent role of metalloproteinase activity. Am. Rev. Respir. Dis. 139:1251-1256.

5. Jones, P. A., and Y. A. DeClerck. 1980. Destruction of extracellular matrices containing glycoproteins, elastin and collagen by metastatic human tumor cell. Cancer Res. 40:3222-3227.

6. Chapman, H. A., J. J. Reilly, and L. Kobzik. 1988. Role of plasminogen activator in degradation of extracellular matrix protein by live human alveolar macrophages. Am. Rev. Respir. Dis. 137:412419.

7. Reilly, J. J., R. W. Mason, P. Chen, L. J. Joseph, V. P. Sukhatme, R. Yise, and H. A. Chapman. 1989. Synthesis and processing of cathepsin L, an elastase, by human alveolar macrophages. Biochem. J. 257:493-498.

8. Mason, R. W., D. A. Johnson, A. J. Barret, and H. A. Chapman. 1986. Elastinolytic activity of human cathepsin L. Biochem. J. 233:925-927. 
9. Mason, R. W., S. Gal, and M. M. Gottesman. 1987. The identification of the major excreted protein from a transformed mouse fibroblast cell line as a catalytically active precursor form of cathepsin $L$. Biochem. J. 248:449-454.

10. Tsuchiya, A., M. Yamabe, Y. Yamaguchi, Y. Kobayashi, T. Konno, and K. Tada. 1980. Establishment and characterization of a human acute leukemia cell line (THP-1). Int. J. Cancer. 26:171-176.

11. Mehta, K., and G. Lopez-Berestein. 1986. Expression of tissue tranglutaminase in cultured monocytic leukemia (THP-1) cells during differentiation. Cancer Res. 46:1988-1994.

12. Swanson, J. A., B. D. Yirinec, and S. C. Silverstein. 1985. Phorbol esters and horseradish peroxidase stimulate pinocytosis and redirect the flow of pinocytosed fluid in macrophages. J. Cell Biol. 100:851-859.

13. Chirgwin, J. M., A. E. Pryzbla, R. J. MacDonald, and W. J. Rutler. 1979. Isolation of biologically active ribonucleic acid from sources enriched in ribonuclease. Biochemistry. 18:5294-5299.

14. Maniatis, T., E. F. Fritsch, and J. Sambrook. 1982. Molecular Cloning. Cold Spring Harbor Laboratory, Cold Spring Harbor, NY. 109-206.

15. Joseph, L. J., L. C. Chang, D. Stamenkovich, and V. J. Sukhatme. 1988. Complete nucleotide and deduced amino acid sequences of human and murine preprocathepsin L: an abundant transcript induced by transformation of fibroblasts. J. Clin. Invest. 81:1621-1629.

16. Fertsch, D., D. R. Schoenberg, R. N. Germain, J. Y. L. Tou, and S. N. Vogel. 1987. Induction of macrophage Ia antigen expression by rIFN-gamma and down-regulation by IFN alpha/beta and dexamethasone are mediated by changes in steady-state levels of Ia mRNA. J. Immunol. 139:244-249.

17. Lowry, D. H., N. J. Rosenbrough, A. L. Farr, and R. J. Randall. 1951. Protein measurement with the Folin phenol reagent. J. Biol. Chem. 193:265-275.

18. Wessel, D., and V. I. Flugge. 1984. A method for the quantitative recovery of protein in dilute solution in the presence of detergent and lipids. Anal. Biochem. 138:141-143.

19. Burnette, W. N. 1977. "Western blotting": electrophoretic transfer of proteins from sodium dodecyl sulfate-polyacrylamide gels to unmodified nitrocellulose and radiographic detection with antibody and radioiodinated protein A. Anal. Biochem. 112:195-203.

20. Gonzalez-Noriega, A., J. H. Grubb, V. Talkod, and S. W. Sly. 1980. Chloroquine inhibits lysosomal enzyme pinocytosis and enhances lysosomal enzyme secretion by impairing receptor recycling. $J$. Cell Biol. 85:839-852.

21. Musson, R. A. 1983. Human serum induces maturation of human monocytes in vitro: changes in cytolytic activity, intracellular lysosomal enzymes, and nonspecific esterase activity. Am. J. Pathol. 111:331-340.

22. Geisow, M. J. 1984. Fluorescein conjugates as indicators of subcellular pH. Exp. Cell Res. 150:29-35.

23. Okhuma, S., and B. Poole. 1978. Fluorescence probe measurement of the intralysosomal $\mathrm{pH}$ on living cells and the pertubation of pH by various agents. Proc. Natl. Acad. Sci. USA. 75:3327-3331.

24. Swanson, J. A., E. Burke, and S. C. Silverstein. 1987. Tubular lysosomes accompany stimulated pinocytosis in macrophages. J. Cell Biol. 104:1217-1222.

25. Ullrich, K., G. Mersmann, E. Weber, and K. von Figura. 1978. Evidence for lysosomal enzyme recognition by human fibroblasts via a phosphorylated carbohydrate moiety. Biochem. J. 170:643-650.

26. von Figura, K., and E. Weber. 1978. An alternative hypothesis of cellular transport of lysosomal enzymes in fibroblasts. Biochem. $J$. 176:943-950.

27. Kaplan, A., D. T. Achord, and W. S. Sly. 1977. Phosphohexosyl components of a lysosomal enzyme are recognized by pinocytosis receptors on human fibroblasts. Proc. Natl. Acad. Sci. USA. 74:20262030.

28. Ohsumi, Y., and Y. C. Lee. 1987. Mannose-receptor ligands stimulate secretion of lysosomal enzymes from rabbit alveolar macrophages. J. Biol. Chem. 262:7955-7962.

29. Campbell, E. J. 1982. Human leukocyte elastase, cathepsin G, and lactoferrin: family of neutrophil granule glycoproteins that bind to an alveolar macrophage receptor. Proc. Natl. Acad. Sci. USA. 79:6941-6945.

30. Ahearn, M. J. 1962. A study of microkinetospheres in HeLa cancer cells. M.A. thesis. University of Texas, Austin.

31. Ahearn, M. J., T. H. Hamilton, and J. J. Biesele. 1966. Seruminduced formation of lysosomes in HeLa cells: a process sensitive to actinomycin D. Proc. Natl. Acad. Sci. USA. 55:852-857.

32. Kornfeld, S. 1987. Trafficking of lysosomal enzymes. FASEB (Fed. Am. Soc. Exp. Biol.) J. 1:462-468.

33. Stahl, P. D., J. S. Rodman, M. J. Miller, and P. H. Schlesinger. 1978. Evidence for receptor-mediated binding of glycoproteins, glycoconjugates, and lysosomal glycosidases by alveolar macrophages. Proc. Natl. Acad. Sci. USA. 75:1399-1403.

34. Campbell, E. J., R. R. White, R. M. Senior, R. J. Rodrigues, and C. J. Kuhn. 1979. Receptor-mediated binding and internalization of leukocyte elastase by alveolar macrophages in vitro. J. Clin. Invest. 64:824-833.

35. Campbell, E. J., and M. S. Wald. 1983. Hypoxic injury to human alveolar macrophages accelerates release of previously bound neutrophil elastase. Am. Rev. Respir. Dis. 127:631-635.

36. Durand, P., A. Pelizza, C. Borrone, and R. Gatti. 1982. I-cell disease and pseudo-Hurler polydytrophy. In Genetic Errors of Glycoprotein Metabolism. P. Durand and J. S. O'Brien, editors. Ediizioni Ermes, Milan. 191-210.

37. Owada, M., and E. F. Neufeld. 1982. Is there a mechanism for introducing acid hydrolases into liver lysosomes that is independent of mannose-6-phosphate recognition? Evidence from I-cell disease. Biochem. Biophys. Res. Commun. 105:814-820.

38. Gabel, C. A., D. E. Goldberg, and S. Kornfeld. 1983. Identification and characterization of cells deficient in the mannose-6-phosphate receptor: evidence for an alternate pathway for lysosomal enzyme targeting. Proc. Natl. Acad. Sci. USA. 80:775-779.

39. McCoy, K. L., and R. H. Schwartz. 1988. The role of intracellular acidification in antigen processing. Immunol. Rev. 106:129-47.

40. Morland, B., and J. Morland. 1978. Selective induction of lysosomal enzyme activities in mouse peritoneal macrophages. J. Reticuloendothel. Soc. 23:469-477.

41. Odessey, R. 1987. Regulation of lysosomal proteolysis in burn injury. Metab. Clin. Exp. 36:670-676.

42. Livi, G. P., J. A. Cardelli, R. C. Mierendorf, and R. L. Dimond. 1985. Regulation of lysosomal alpha-mannosidase-1 synthesis during development in Dictyostelium discoideum. Dev. Biol. 110:514-520.

43. Baron, R., L. Neff, W. Brown, P. J. Courtoy, D. Louvard, and M. G. Farquhar. 1988. Polarized secretion of lysosomal enzymes: codistribution of cation-independent receptors and lysosomal enzymes along the osteoclast exocytic pathway. J. Cell Biol. 106:1863-1872.

44. Siripont, J., J. M. Tebo, and R. F. Mortensen. 1988. Receptormediated binding of the acute-phase reactant mouse serum amyloid P-component to macrophages. Cell. Immunol. 117:239-252.

45. Yednock, T. A., L. M. Stoolman, and S. D. Rosen. 1987. Phosphomannosyl-derivatized beads detect a receptor involved in lymphocyte homing. J. Cell Biol. 104:713-723.

46. Saraiva, E. M., A. F. Andrade, and W. de Souza. 1987. Involvement of the macrophage mannose-6-phosphate receptor in the recognition of Leishmania mexicana amazonensis. Parasitol. Res. 73:411416.

47. MacDonald, R. G., S. R. Pfeffer, L. Coussens, M. A. Tepper, C. M. Brocklebank, J. E. Mole, J. K. Anderson, E. Chen, M. P. Czech, and A. Ullrich. 1988. A single receptor binds both insulin-like growth factor II and mannose-6-phosphate. Science (Wash. DC). 239:11341136.

48. Kuhlman, M., K. Joiner, and R. A. Ezekowitz. 1988. The human mannose-binding protein functions as an opsonin. J. Exp. Med. 169:1733-1745.

49. Muller, W. E., K. Renneisen, M. H. Kreuter, H. C. Schroder, and I. Winkler. 1988. The D-mannose-specific lectin from Gerardia savaglia blocks binding of human immunodeficiency virus type I to H9 cells and human lymphocytes in vitro. J. Acquired Immune Defic. Syndr. 1:453-458. 